\title{
Atmospheric icing status and type of southwest China networks
}

\author{
Yawei $\mathrm{Li}^{1}$, Xinghai Zhang ${ }^{1}$, Peng Zhou ${ }^{2}$, Lei Sun ${ }^{2}$ and Longchen Liu ${ }^{1}$ \\ ${ }^{1}$ Electric Power Research Institute of State Grid Sichuan Electric Power Company, 610072 Chengdu, China \\ ${ }^{2}$ Graduate School at Shenzhen, Tsinghua University, 518055 Shenzhen, China.
}

\begin{abstract}
Transmission line disconnection, tower collapse and insulator flashover caused by icing seriously threaten power system security. Ice type and state of transmission lines, which vary a lot with terrain and climate, in typical areas such as Daqing-ridge, Yak Mountain and Erlang Mountain in Sichuan Province in South China were investigated in this paper. It is shown that mixed-phase ice with obvious layered structure, low density, strong adhesive force and windward-side growth is the main type of ice threatening the security of transmission lines and insulators. There is more ice on the ends of insulators than other areas in severe cases, where all sheds of the insulator is bridged by ice. Besides, temperature, humidity and precipitation intensity are main factors influencing the icing process. As a result, terrain and climate play a leading role in determination of icing type and severity.
\end{abstract}

\section{Introduction}

In China, geographical distribution of energy presents a serious imbalance. The load centers are in concentrated distribution in the southeastern coastal strip, far away from southwest regions where clean hydropower resource is rich. Therefore, in order to meet the energy needs of economic production, EHV and UHV long distance transmission is a must for China. Under the influence of geographical environment in the south-western China, EHV and UHV transmission lines will inevitably go through high altitude areas, canyons, rivers and other regions with complex geography and climate, which leads ice-covered insulator to high flashover risk.

For example, Sichuan, a province with vast territory in south-western China, crosses the first and the second step in the three-step terrain of China, which makes the climate conditions of Sichuan power grid vary widely. In western Sichuan plateau areas, $20 \mathrm{~mm}$ and above heavy ice areas of transmission lines widely distributes. For instance, AC 500kV Gan-Shu line go through $10 \mathrm{~mm}$ ice area from 019 tower to 022 tower, through $20 \mathrm{~mm}$ ice area from 022 tower to 023 tower, through $40 \mathrm{~mm}$ ice area from 023 tower to 024 tower, through $60 \mathrm{~mm}$ ice area from 024 tower to 033 tower, through $40 \mathrm{~mm}$ ice area from 033 tower to 040 tower, and through $20 \mathrm{~mm}$ ice area from 040 tower to 044 tower It shows that icing conditions of transmission lines in Sichuan region are very complex, which makes the anti-icing modification of transmission lines very difficult.

To reduce the loss of icing disaster, Sichuan Electric Power Company carried out a lot of anti-icing modification of transmission lines. By the end of 2012, the modification of $17500 \mathrm{kV}$ lines and $2220 \mathrm{kV}$ lines had been completed, which enhanced the anti-icing ability of Sichuan power grid. However, under the influence of regular change of climate conditions in Sichuan Province, the anti-icing modification is a longterm and arduous work in some degree. Under the influence of several times of cold-air outbreak from December of 2013 to March of 2014, ice flashover of $500 \mathrm{kV}$ transmission lines occurred 23 times in total, including 2 times from Gan-Shu 1st and 2nd line, 9 times from Cheng-Mu 1st and 2nd line. Since 1950s, many countries in the world, China included, have researched on icing of transmission lines and achieved many important results [1-7]. But so far, icing mechanism on transmission lines and insulator strings, flashover characteristics of ice-covered insulator strings and many other problems are still far from resolved [8-16], and there is almost no understand about the icing reasons of power grid under microtopography and micrometeorology conditions [9].

It can be seen that, under the influence of complex topography and changeable weather conditions, icing situation in south-western China power grid is complex [17-19]. Therefore, in order to understand ice forms, characteristics and formation conditions under microtopography and micrometeorology conditions in south-western China, the paper conducted the research on the icing conditions of several selected typical regions, including Daqing-ridge in Xichang City (altitude 2500m), Yak Mountain (altitude $3100 \mathrm{~m}$ ), Erlang Mountain (average altitude $3000 \mathrm{~m}$ ) and Luding County. Icing process of transmission lines and conditions in these areas is observed and recorded and icing accidents in these areas in recent are analysed and researched, in order to develop a targeted anti-ice strategy for power grid. 


\section{2 lcing morphology on transmission lines and insulators}

At the initial stage of icing, ice, especially on the transmission lines, grows in bifurcation. Fig. 1(a) shows the initial stage of icing on the $500 \mathrm{kV}$ Cheng-Mu 1 st line in Daqing-ridge.

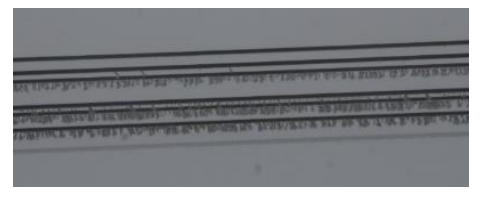

(a) initial stage of icing

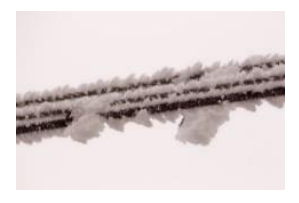

(b) later stage of icing
Figure 1. Structure of ice on the wire at early and late stage.

Fig. 1(b) shows the later stage of icing on the $500 \mathrm{kV}$ 4-bundle conductor. The icing is loose and porous with layered structure, closely sticked to conductor surface.

Ice is formed by condensation water droplets or ice crystal stacked in the object surface. Drops and ice crystal in the air are wrapped with forward movement of air (wind), so ice distribution on insulator strings has a close relationship with wind direction. The upwind side of insulator is not blocked and drops and ice crystal are more easily to cumulate, so ice on conductors and insulators is mainly distributed on their upwind surface, as shown in Fig. 2 below.

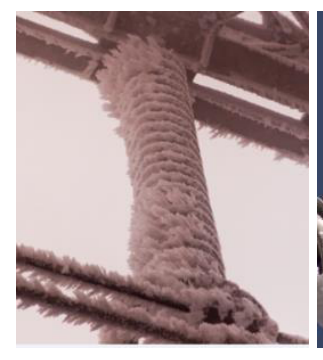

(a) "I" string

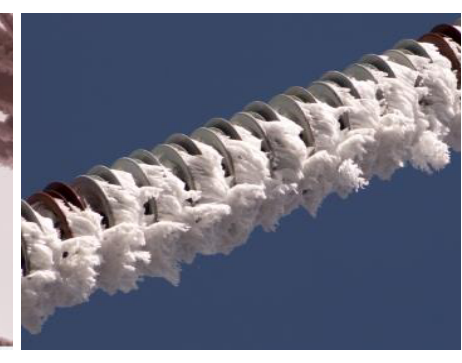

(b) one hand of "V" string
Figure 2. Icing conditions of transmission lines and insulators.

The left picture of Fig. 2 is an "I" string consist of bell-shaped glass insulators on tower 131 in Shi-Ya 4th line, while the right picture is a "V" string consist of three umbrella-shaped porcelain insulators on Tower 69 in $\pm 800 \mathrm{kV} \mathrm{Jin}-\mathrm{Su}$ line. It shows that icing is more serious in windward side than that-in leeward side

Fig. 2 also shows icicles exist in the ice, which implicates that melting and freezing due to temperature changes exist in the icing process. This is also one of the way to form-layered mixed-phase ice under natural icing conditions. This phenomenon not only exists in the icing of conductors, but also commonly exists on the surface of insulator strings, as shown in Fig. 3.

In Fig. 3, the left picture shows the windward side of a "V" string of $\pm 800 \mathrm{kV}$ Jin-Su line, and the right picture shows the bottom side of an "II" string of 500kV Yue-Pu line. It can be seen that icicles exist widely along different insulator strings. The existence of icicles increases the probability of bridged insulator and flashover.

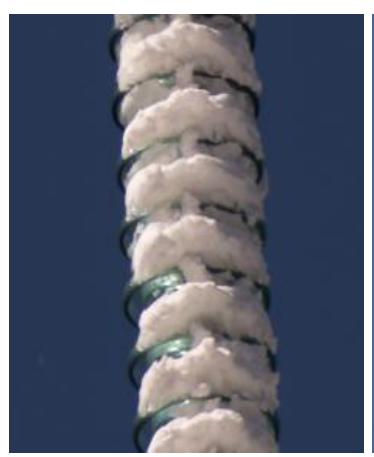

(a) V string

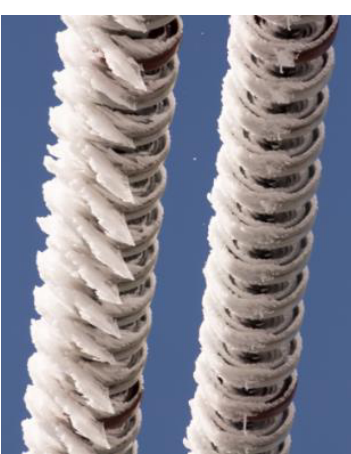

(b) II string
Figure 3. Icicles along insulator strings.

Fig. 4 shows a flowered glass insulator string in the period of icing and melting. At early stage of not serious icing, the large sheds can prevent entire string from being bridged. However, under serious icing conditions, the large and small sheds are all covered by ice, thus the block effect of large sheds is limited.
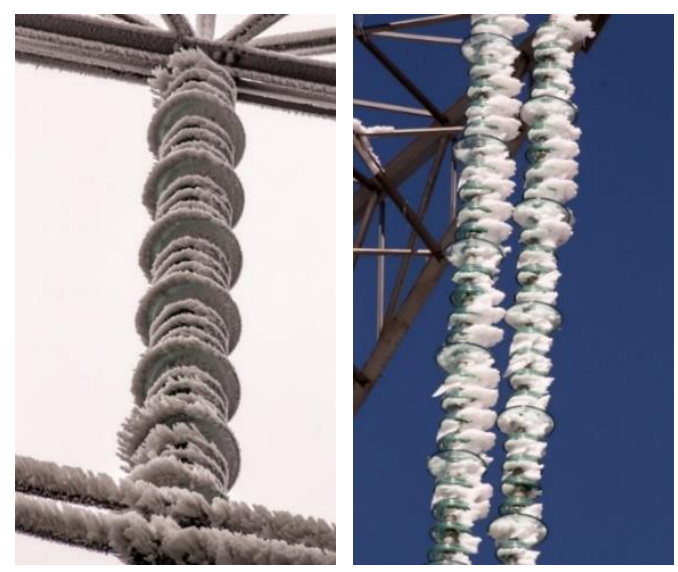

Figure 4. Icing conditions of flower arrangement insulator strings at early and late stage.

Fig. 5 shows that icing is more on ends of insulator strings, where the electrical field is stronger. (a) tension strings

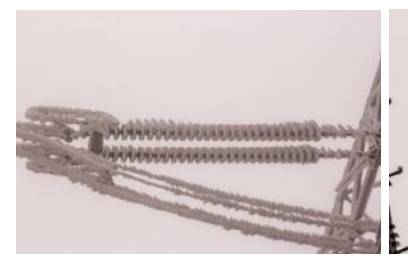

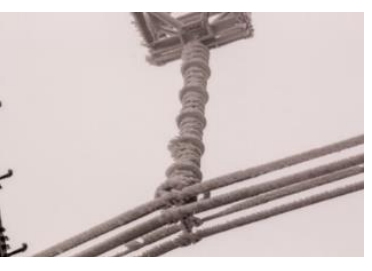

(b) I string
Figure 5. Axial distribution of ice along insulator strings.

\section{The type and characteristics of icing on lines and insulators}

In the field research of icing circumstances on lines and insulators in Daqing-ridge, Erlang Mountain and Luding County, it is found that icing has layered structure, as shown in Fig. 6. The outer layer of ice has a loose and porous structure and white appearance, while the inner layer of ice, which adheres to conductors or insulator 
sheds, has a dense structure and transparent or semitransparent appearance.

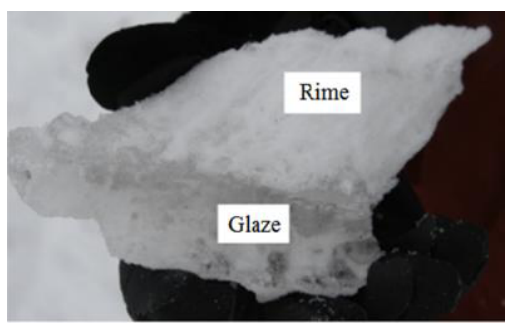

Figure 6. Structure of mixed-phase ice.

The density of ice dropped from tower was measured by drainage in field research. The results show that-the density of ice ranges from $0.5 \mathrm{~g} / \mathrm{cm}^{3}$ to $0.6 \mathrm{~g} / \mathrm{cm}^{3}$.

Based on characteristics above, it can be concluded that ice on transmission lines and insulator strings mainly consists of mixed-phase ice (hard rime) [9, 16].

In the research of icing conditions in Yak Mountain, it is found that ice in this area mainly consists of rime, and its appearance is shown in Fig. 7.

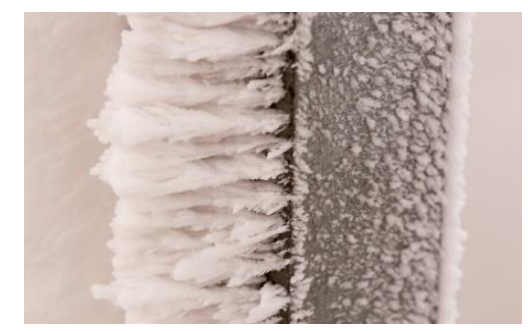

Figure 7. Rime ice in the Yak Mountain Weather Stations.

The ice shown in Fig. 7 has a weak adhesion and small density, and it is very easy to drop down from conductors or insulators. The statistics of icing from 2013 to 2015 show that the thickness of ice is not more than $50 \mathrm{~mm}$, and no flashover accidents happened due to rime, while several accidents because of transmission lines disconnection and tower collapse happened in Daqingridge. At another spot, several flashover accidents of icecovered insulators happened in Erlang Mountain.

The conductivity of ice example dropped from transmission towers in Erlang Mountain was measured. The result is shown in table 1. In the table, the melting water of glaze and rime is obtained by separating the mixed-phase ice.

Table 1. Conductivity of melting ice water of snow and ice at $20^{\circ} \mathrm{C}\left(\mu \mathrm{s} \cdot \mathrm{cm}^{-1}\right)$.

\begin{tabular}{|c|c|c|c|}
\hline Sample spot & rime & glaze & snow \\
\hline Shi-Ya $4^{\text {th }}$ No.132 & 66.25 & 14.19 & 48.32 \\
\hline Shi-Ya $2^{\text {nd }}$ No.115 & 64.22 & 15.13 & 47.54 \\
\hline Shi-Ya $3^{\text {rd }}$ No.130 & 67.83 & 15.61 & 50.63 \\
\hline
\end{tabular}

\section{The analysis of ice forming conditions}

\subsection{Temperature and humidity}

In 2014 at Shi-Ya 4th line, icing process corresponds to low temperature periods, which was observed at transmission line monitoring spots, as shown in Fig. 8. In addition, the lowest temperature in January is $-6^{\circ} \mathrm{C}$, and the corresponding maximum ice thickness is $6.5 \mathrm{~mm}$. While the lowest temperature in February is $-4^{\circ} \mathrm{C}$, and the corresponding maximum ice thickness is $11 \mathrm{~mm}$. This implicates that icing doesn't go more serious when temperature goes down.

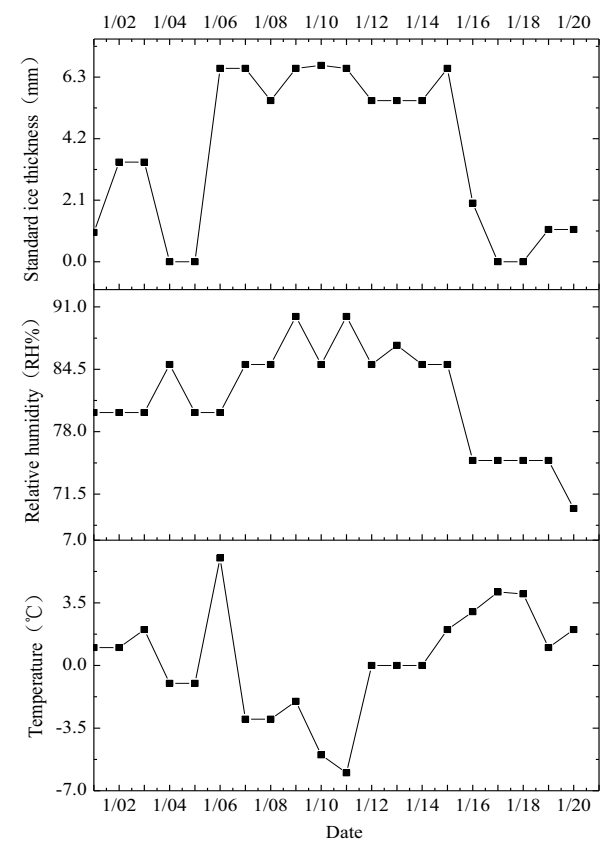

Figure 8. monitoring results of Shi-Ya $4^{\text {th }}$ line.

The research of Yak Mountain 2nd line shows that, the formation and increase of ice has a close relationship with temperature change, at the same time, humidity at a relatively high level is necessary. About Jan $10^{\text {th }} 2014$ in Yak Mountain 2nd line, icing increased when temperature changed from $3^{\circ} \mathrm{C}$ to $0^{\circ} \mathrm{C}$, as shown in Fig. 9 . In the meantime, relatively high humidity provided water droplets and ice crystal for icing. This concludes that relatively low temperature and necessary humidity are basic factors for icing. In the icing process on Feb $17^{\text {th }}$ and $18^{\text {th }}$, similar phenomenon occurred that temperature fell correspondingly to icing. Despite that the lowest temperature $-3^{\circ} \mathrm{C}$ during the two days is lower than that of Jan $10^{\text {th }} 0^{\circ} \mathrm{C}$, however ice thickness in February $1 \mathrm{~mm}$ is thinner than that in January $2 \mathrm{~mm}$.

As temperature rose, ice amount, at first rose and then fell. Maybe it's because the dry growth and wet growth is sensitive to temperature changes. At lower temperature, dry growth plays a more significant role in icing and icing water has a relatively poor mobility, while at higher temperature, wet growth become more important in icing and icing water has a stronger mobility. But at both circumstances, icing growth is inhibited. This implies that there is a temperature range where it's most favourable for icing.

Besides, the contrast of research results in January and February implies that humidity has significant influence on icing. On the whole, icing amount in a 
month with higher humidity is bigger than that in a month with lower humidity.

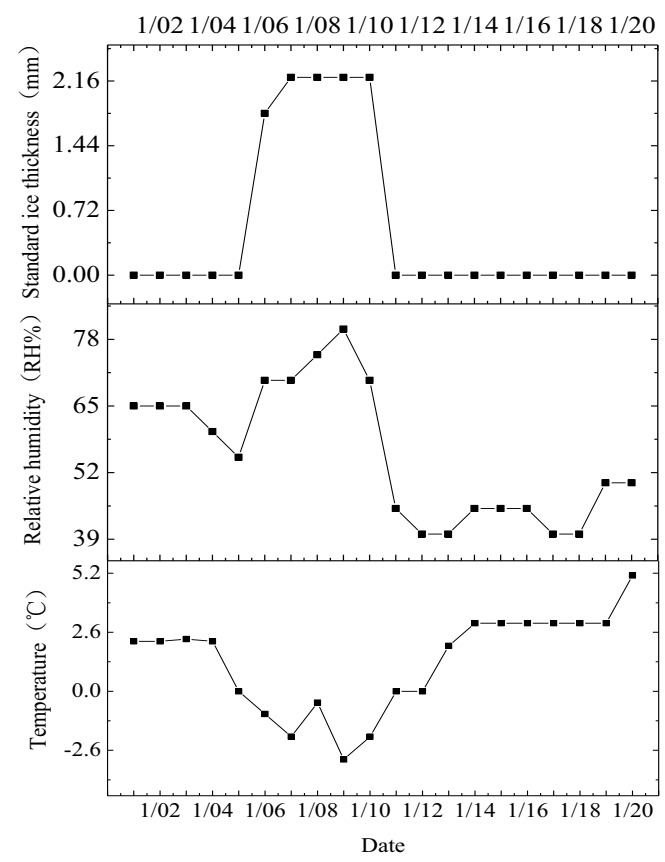

Figure 9. Monitoring results of Yak Mount $2^{\text {nd }}$ line.

\subsection{Precipitation and morphology}

The altitude of the weather station in Yak Mountain is about $3100 \mathrm{~m}$, and the station is at summit where other summits around are lower. As a result, the weather station is often heavily foggy, has a little precipitation and low temperature. So icing in the area mainly consists of rime by dry growth, and wet growth seldom exists.

Daqing-ridge is a typical alpine gorge, and the gorge is open to Qionghai Lake and Xichang urban area where the terrain is more open. The air carried water vapor from Qionghai Lake is lifted and forms a quasistationary front. This results in increase precipitation in the gorge in winter and rain, snow and heavy fog appears alternately, which is beneficial to icing accumulation with dry and wet growth. As a result, icing on the transmission lines and towers is often very serious.

From Feb. 13th to Mar. 7th in 2014, 9 ice flashover occurred on $500 \mathrm{kV}$ Gan-Shu 1st and 2nd line. The flashover fault section is in the north side of the mountain in Erlang Mountain, where the altitude ranges from $2326 \mathrm{~m}$ to $2889 \mathrm{~m}$. The terrain is at the cross of mountains and river valleys and climate change there is severe. At that spot, icing is common in winter and heavy fog is common at night. It is a typical easyily-icing microtopography and micrometeorology region.

It can be seen that icing often occurs at summits with high altitude, where precipitation is small and temperature is low. It's easier to form rime, while in the gorges and at the cross where mountains and river valleys joint, heavy mixed-phase ice is easier to form under the influence of quasi-stationary front.

\section{Conclusion}

Aimed at the circumstance and the diversity of icing appearance and types on power grid under complex morphology and geological condition in south-western China, the article undertook researches on icing conditions in Daqing-ridge, Yak Mountain and Erlang Mountain. The conclusions are as follows:

1)Icing on Sichuan power grid mainly consists of mixed-phase ice with inner glaze layer and outer hard rime layer.

2)As temperature rises, icing amount increases first and then decreases. At the same temperature, icing amount increases when humidity increases.

3)Rime is easier to form at summit, while mixedphase is easier to form in gorges and the cross of mountains and river valleys.

\section{References}

1. Sun Caixin, Sima Wenxia, Shu Lichun. Atmospheric environment and electrical insulation. M. Beijing: China Electrical Press, 2002.

2. Shu Lichun, Jiang Xingliang, Tian Yuchun, et a. AC flashover performance and voltage correction of four types of iced composite insulator at altitude $4000 \mathrm{~m}$ above. J. Proceedings of the CSEE, 2004, 24(1): 97101.

3. Li Peng, Fan Jianbin, Su Zhiyi, et al. Insulation design in icing areas for $750 \mathrm{kV}$ transmission lines [J]. Electrical Equipment, 2002, 8(3): 9-133

4. Farzaneh, M., Chisholm, W. A. Insulator icing test methods, selection criteria and mitigation alternatives [J]. IEEE Transactions on Dielectrics and Electrical Insulation, 2007, 14(6): 1462-1473.

5. Farzaneh, M. Atmospheric Icing of Power Networks. M. Berlin: Springer, 2008.

6. S. Taheri, M. Farzaneh, I. Fofana. Improved dynamic Model of DC Arc Discharge on ice-covered post insulators surfaces $[\mathrm{J}]$. IEEE Transactions on Dielectrics and Electrical Insulation, 2014, 21(2): 729-739.

7. Azam Nekahi, Shahab Farokhi, Masoud Farzaneh, et al. Arc Energy and temperature during its propagation over ice-covered surfaces [J]. IEEE Transactions on Dielectrics and Electrical Insulation, 2014, 42(1): 114-119.

8. Farzaneh M., Kiemicki J. Flashover problems caused by ice build-up on insulators [J]. IEEE Electrical Insulation Magazine, 1995, 11(2): 5-17.

9. Wu Xiangdong, Xu Tianyong, Ai Zhiping. The influence of ice-covering on $500 \mathrm{kV}$ transmission line in micro-terrain and micro-weather area and the countermeasure. J. High Voltage Engineering, 2002, 28(7): 55-57.

10. Ndiaye I., Farzaneh M., Fofana I., Study of the development of positive streamers. IEEE Transactions on Dielectrics and Electrical Insulation. J. 2007, 14(6): 1436-1445.

11. Farzaneh M., Chisholm A. W. Insulators for Icing and Polluted Environments. M. Hoboken, New Jersey: John Wiley \& Sons, Inc., 2009. 
12. Masoud Farzaneh, William A. Chisholm. 50 years in icing performance of outdoor insulators [J]. IEEE Electrical Insulation Magazine, 2014, 30(1): 14-24.

13. Zuoming $\mathrm{Xu}$, Tao $\mathrm{Xu}$, Wei $\mathrm{Hu}$, et al. Study on dynamic flashover model of ice-covered insulator string [C]. 2013 Annual Report Conference on Electrical Insulation and Dielectric Phenomena, 2013, Shenzhen, China.

14. Kangning Wang, Tianzheng Wang, Yu Deng. The mechanism of salt migration phenomena in cooling water and its impact on ice flashover [C]. 2013 IEEE International Conference on Solid Dielectrics, 2013, Bologna, Italy.

15. S. Taheri, M. Farzaneh, I. Fofana. Equivalent Surface Conductivity of Ice Accumulated on insulator during development of $\mathrm{AC}$ and $\mathrm{DC}$ Flashover arcs [J]. IEEE Transactions on Dielectrics and Electrical Insulation, 2013, 20(5): 1789-1888.
16. Kangning Wang, Tianzheng Wang, Yu Deng, et al. Melting process of multi-Icicles and its flashover performance [C]. 2013 Annual Report Conference on Electrical Insulation and Dielectric Phenomena, 2013, Shenzhen, China.

17. László E. Kollár, Masoud Farzaneh, Pierre Van Dyke. Modeling ice shedding propagation on transmission lines with or without interphase spacers [J]. IEEE Transactions on Power Delivery, 2013, 28(1): 261 267.

18. Yu Deng, Zhidong Jia, Hao Jiang, et al. Melting process of different icing morphology and its impact on ice flashover [J]. High Voltage Engineering, 41(2): 669-679.

19. Xingliang Jiang, Bingbing Dong, Zhijin Zhang, et al. Research and development on flashover of icecovered insulators [J]. High Voltage Engineering, 40(2): 317-335. 